\title{
LA ASUNCIÓN DE MOGUER, OBRA DE JUAN ANTONIO. SÍNTESIS DE SU VIDA Y QUEHACER ARTÍSTICO
}

\author{
POR JUAN MigUEL GONZÁLEZ GóMEZ
}

\begin{abstract}
El presente trabajo tiene como objetivo prioritario el estudio del gran cuadro de la Asunción de la Virgen, realizado entre 1993 y 1995 por el pintor sevillano Juan Antonio Rodríguez. Con tal motivo, el artículo se divide en tres apartados. En el primero facilitamos una aproximación a la biografía del autor. En el segundo aportamos referencias estilísticas y valoraciones críticas sobre su variada producción artística. Y, por último, acometemos el análisis iconográfico, compositivo y formal de la obra en cuestión.

The aim of this paper is to study the great painting of the Assumption of the Virgin Mary done by the Sevillian painter Juan Antonio Rodríguez between 1993 and 1995. The article is composed of three section contains an approach to the author's biography. The second one offers stylistic and critical references on his artistic producction. Finally, in third section presents an iconographic analysis of the painting.
\end{abstract}

Desde los lamentables sucesos de 1936 hasta nuestros días, la cabecera de la monumental iglesia parroquial de Moguer, edificio representativo de la arquitectura sevillana del Setecientos, ha permanecido desnuda. Ahora, gracias a los desvelos y afanes del actual cura párroco, don Manuel Castilla Bonaño, para conservar y embellecer el inmueble, se exoma con un gran cuadro de la Asunción de María, pintado por Juan Antonio Rodríguez. De esta forma, con la ayuda de un nutrido grupo de feligreses, se potencia su escueto patrimonio artístico y se contribuye a la solemnización de las celebraciones litúrgicas.

Con tal motivo, al acometer el estudio de esta obra, de tamaño colosal, por razones expositivas, creemos oportuno facilitar una visión de conjunto, tanto del aspecto biográfico como de la variada y rica producción artística del autor. 


\section{PINCELADAS BIOGRÁFICAS.}

Juan Antonio Rodríguez Hernández, hijo del pintor Rafael Blas Rodríguez Sánchez y de Amalia Hernández Amado, nació en Sevilla el 11 de octubre de 1922. Tanto él como su hermano Rafael aprendieron el oficio de la pintura junto a su padre ${ }^{1}$. Nuestro artista completó sus conocimientos en la Escuela de Artes Aplicadas y Oficios Artísticos de esta ciudad. Y, posteriormente, al fundarse la Escuela Superior de Bellas Artes en 1940, formó parte de la primera promoción de la misma. En 1946 obtuvo, en dicho centro, el título académico de profesor de Dibujo, con premio al mejor expediente de dicha promoción.

De inmediato, se independiza y comienza a recibir múltiples encargos. Como era de esperar, a lo largo de su trayectoria profesional, avalada por una obra bien hecha, ha cosechado importantes premios y distinciones honoríficas. Al terminar sus estudios, en 1946, obtiene el premio "Ybarra" para pintores. Acto seguido, en 1947 y 1948, concurre a la Exposición de Primavera, consiguiendo sucesivamente en ambas muestras el premio "Gonzalo Bilbao", del Excmo. Ayuntamiento de Sevilla. Gracias a ello, estudia paisaje en Guadalupe (Extremadura) y Galicia.

En 1948, además, le asignan el premio "Bartolomé Esteban Murillo", de la Excma. Diputación Provincial, con lo cual amplía estudios artísticos en Mallorca. Por entonces, influido por el dibujante José Bover, opta por un nuevo lenguaje pictórico, donde la línea se impone al color. En 1950 y 1951 expone individualmente en Madrid, en los Salones Alcor y Dardo, respectivamente. Un año después, en 1952, presentó La Anunciación a la Exposición Universal de Arte Sacro, en el Vaticano. Más tarde, en 1955, cuelga sus obras en la Sala Ateneo, de Sevilla; y participa en la muestra colectiva "Tipos y paisajes de España", en la Galería Toisón, de Madrid. Y consiguió, en la Primera Exposición de Estampas de Navidad, celebrada en Madrid en 1956, una medalla de plata.

Entre 1956 y 1972 trabaja intensamente para la República Venezolana. Su vinculación artística con ese país hispanoamericano se efectuó a través del Hno. Nectario María, gran admirador de la obra de Juan Antonio. Sus pinturas religiosas, históricas y retratos figuran desde entonces en museos, ayuntamientos, universidades y colecciones particulares de Venezuela ${ }^{2}$. Todo ello explica que en 1957, como reconocimiento a su labor pictórica para el Gobierno Venezolano, se le conceda un nombramiento como Miembro Efectivo, condecorado, del Instituto Venezolano de Cultura Hispánica ${ }^{3}$.

1. GONZÁLEZ GÓMEZ, Juan Miguel: "Varios bocetos de Rafael Blas Rodríguez. Una aproximación a su vida y obra", en Rev. Laboratorio de Arte. $\mathrm{n}^{\circ}$ 5. Tomo II. Sevilla, 1992, pp. 245-266.

2. MAÑES MANAUTE, Antonio: "La pintura religiosa e histórica de Juan Antonio Rodríguez en Huelva y Venezuela", en Andalucía y América en siglo XX. Sevilla, 1987, pp. 323-352.

3. (A)rchivo (P)articular (J)uan (A)ntonio (S)evilla. Libro $1^{\circ}$ de Exposiciones, Crónicas y Críticas. Carta fechada en Caracas a 20 de diciembre de 1957, en la que se le notifica el nombramiento. El escrito está firmado por Rafael Paredes Urdaneta, Secretario General del Instituto Venezolano de Cultura Hispánica. 
Más tarde, en 1961, disfruta la beca "Diego Velázquez", de la Excma. Diputación Provincial de Sevilla, para completar su formación en Roma. Tras un nuevo intento de cambio en el estilo pictórico, recobra definitivamente sus habituales maneras. Y, al año siguiente, en 1962, le otorgan el primer premio de pintura en la Exposición Nacional de Arte de Jaén, a su obra titulada Anunciación ${ }^{4}$.

Con posterioridad, en 1977, organiza otra muestra individual en la Galería Amplitud, de Sevilla. Y, en 1978, el Excmo. Ayuntamiento de Moguer le impone una medalla de plata por su intervención en el IX Salón de Pintura y Escultura Andaluza, celebrado en el Monasterio de Santa Clara de dicha ciudad. De inmediato, en 1979, tiene lugar su exposición individual en la Galería Bética, en Madrid. Y en 1980 interviene en varias muestras: en una individual, en Sevilla, en la Galería de Arte Magdalena Mesa; en otra colectiva, titulada "Seis pintores para tres temas", en la sevillana Galería de Arte Haurie; en otra personal en la Galería Al-Andalus, de Granada; en otra colectiva, en Quito, en una exposición sobre " $E$ l intimismo en la pintura española en los siglos XIX y XX"; etc.

En 1981 expone individualmente en la Galería Toscana, en Valencia. Un año después, en 1982, obtiene en la Exposición de Otoño, en Sevilla, por su obra Adolescencia, el premio "Dirección General de Bellas Artes" 5 . Y ese mismo año presenta en Bilbao su extraordinario "Homenaje a la Ópera", en Caledonia, Galería de Arte ${ }^{6}$. Acto seguido, en 1983, expone, en El Monte de Piedad y Caja de Ahorros de Sevilla, en otra colectiva, denominada "Dibujos de pintores sevillanos". A continuación, en 1984 y 1985, vuelve a mostrar sus obras en el madrileño Estudio de Arte, Peironcely. Y se mantiene en esa línea, ya que en 1986 figura en "Homenaje a Álvaro", en la sevillana Galería Álvaro. Y en 1987 participa nuevamente en la Exposición de Otoño, de la Real Academia de Bellas Artes de Sevilla, donde es distinguido con el premio de "La Real Maestranza de Caballería" 7

Entre diciembre de 1987 y enero de 1988 interviene en otra colectiva, sobre "Pintores andaluces", en Bilbao, en Caledonia, Galería de Arte. En 1988 forma parte de otra colectiva, denominada, "El dibujo y la poesía en el canto por sevillanas", en Caja San Fernando, de Sevilla. Poco después, en 1989, aparece en la colectiva "Artistas en Sevilla", en Mairena del Aljarafe. Y en 1990, organiza en Madrid dos interesantes exposiciones: una, antológica de sus dibujos y pinturas, con

4. AGUDO, Antonio: “Apuntes para una biografía de Juan Antonio", en Juan Antonio. Tabapress, Grupo Tabacalera. Colección Patio de la Cultura, $N^{\circ}$ 5. Madrid, 1990, pp. 25-30.

5. A. P. J. A. S.: Libro $2^{\circ}$ de Exposiciones, Crónicas y Críticas. Oficio firmado por José Hernández Díaz, presidente de la Real Academia de Bellas Artes de "Santa Isabel de Hungria", de Sevilla, con fecha 10 de noviembre de 1982.

6. LORENTE, Manuel: "Juan Antonio: Homenaje a la Ópera", en diario ABC. Sevilla, 25-VIII-1982.

7. A.P. J. A. S.: Libro $2^{\circ}$ de Exposiciones, Crónicas y Críticas. Título de la Real Academia de Bellas Artes de Santa Isabel de Hungría, de Sevilla, acreditativo del premio de "La Real Maestranza de Caballería", firmado por José Hernández Díaz, como presidente de dicha corporación académica, con fecha 17 de noviembre de 1987. 
motivo de sus Bodas de Oro con las Bellas Artes, en el Patio de la Cultura de Tabacalera ${ }^{8}$; y otra, de "Flores y Bodegones" en Durán, Exposiciones de Arte".

En 1991 pintó también el paño de la Verónica, para la Hermandad del Valle, de Sevilla ${ }^{10}$. Poco antes, donó la obra titulada Recuerdo Romántico para la creación de una Galería de Arte Contemporáneo en la Universidad de Sevilla, inaugurada el 3 de abril de 1991, compuesta por sesenta y tres obras de profesores de la Facultad de Bellas Artes de la Hispalense ". En 1992 participa en una muestra colectiva sobre "Siete pintores sevillanos actuales", en Caledonia, Galería de Arte, de Madrid ${ }^{12}$. Y, finalmente, en 1995 interviene en otra exposición colectiva denominada "La Mitología Clásica en la Pintura y Escultura Actuales", en el Centro Cultural Galileo, de Madrid ${ }^{13}$.

Como todo buen maestro, durante varios años alternó la actividad creadora con la docente. En este sentido, ejerció como profesor de Dibujo en el Colegio Alfonso X, el Sabio, de Sevilla; y como profesor auxiliar en la Cátedra de Colorido de la Escuela Superior de Bellas Artes de Santa Isabel de Hungría, de Sevilla, hoy transformada en Facultad de Bellas Artes de la Universidad Hispalense ${ }^{14}$.

\section{REALISMO POÉTICO}

Juan Antonio cuenta en su haber con una fecunda y acertada labor pictórica. En su obra artística —intensa y extensa - hay pintura religiosa, histórica, mitológica y costumbrista; paisaje, retrato, floreros y bodegones. Y nos deleita, siempre, con su estilo realista. Es el suyo un realismo poético, impregnado de exquisita sensibilidad y refinada elegancia. En sus obras, de cuidada factura, logra con naturalidad la ambientación y atmósfera apetecidas. Y rehuye intencionadamente la vulgaridad de lo cotidiano. Por consiguiente, su pintura, plena de alegría, optimismo y belleza, es un canto a la vida.

Que ésto es cierto lo confirma el mismo artista, cuando dice: "Siempre ha sido así, pues cuando he intentado cambiar, no tardé en darme cuenta de que era una tontería. Por eso he procurado mantener mi propia personalidad, por encima de todo, aceptando, por supuesto, aquellas influencias que iban bien con mi carácter, con mi

8. VV. AA.: Juan Antonio. Tabapress, Grupo Tabacalera. Colección Patio de Cultura, $\mathrm{n}^{\circ}$ 5. Madrid, 1990.

9. GONZÁLEZ GÓMEZ, Juan Miguel: Juan Antonio. Floreros y Bodegones. Catálogo Durán, Exposiciones de Arte. Madrid, 1990.

10. GONZÁLEZ GÓMEZ, Juan Miguel: "Imaginería de las Cofradías sevillanas desde el Academicismo al Expresionismo realista", en las Cofradías de Sevilla en el siglo de las Crisis. Sevilla, 1991, p. 1974.

11. A. P. J. A. S.. Libro $2^{\circ}$ de Exposiciones, Crónicas y Críticas. Oficio firmado por el rector Javier Pérez Royo con fecha 10 de junio de 1991.

12. Rev. Antiquaria. Año X, n 91 , Madrid, 1992, p. 80.

13. GALLARDO LÓPEZ, $\mathrm{M}^{2}$ Dolores: La mitología clásica en la pintura y escultura actuales. Ediciones Clásicas. Madrid, 1995, pp. 84-85.

14. GONZÁLEZ GÓMEZ, Juan Miguel: "Imaginería de la Semana Santa de Sevilla en la segunda mitad del siglo XX", en Las Cofradías de Sevilla en el siglo XX. Sevilla, 1992, pp. 281 y 282. 
deseo de hacer una pintura muy razonada y equilibrada, respetando mucho las formas de la naturaleza. En mi pintura - continúa diciendo - participa mucho la cosa escultórica, los relieves y los volúmenes. Como entiendo que la obra de arte tiene que poseer belleza y poesía me gusta pintar las cosas pimpantes, las flores, las mujeres hermosas, la juventud. Todo lo que es bello y amable. Eso es lo que trato de reflejar en mis obras, sin necesidad de ser inquisitivo, de intentar descubrir algo nuevo, pues lo único que hay que descubrir es la propia personalidad" 15 .

Antonio Oliver estima que el tema religioso es lo más representativo del quehacer artístico de Juan Antonio. Sus escenas religiosas, de correcto dibujo y luminoso colorido, "no nos recuerdan nada de la pintura clásica, ni de la que en el siglo pasado dejaron los pinceles de los maestros españoles, desde Maella hasta Palmaroli. Es cosa diferente, y ello quiere decir que es original siendo clásica, es decir, académica" 16 .

Entre sus pinturas religiosas podemos citar las trece del altar mayor de la parroquia de Villanueva de la Serena (Badajoz) y las ocho del retablo principal de la iglesia de Ntra. Sra. del Reposo, de Valverde del Camino (Huelva), (1950); más dos cuadros que completan el presbiterio de la misma: Dormición y Asunción de la Virgen (1955). El retablo de la Presentación de Jesús en el Templo y Purificación de Maria, de la iglesia del Asilo de Huelva, concebido a modo de tríptico (1981). La Sagrada Familia del templo de Santa Teresa, de Huelva (1981). Los dos cuadros de la capilla mayor, del Sagrario, de Catedral de Sevilla: San Juan de Ribera y San Pío X. Otra versión de San Pío X para el Palacio Arzobispal de nuestra ciudad. Dos retablos-marcos en la capilla de los marineros de Triana: Las Ánimas del Purgatorio y la Coronación de la Virgen (1965), etc.

Por todo ello, Carmen Laffont comenta que Juan Antonio, en su afanosa producción, simultanea "retablos, retratos, cuadros de historia, etc., realizados todos con gran dignidad, con obras más espontáneas y personales donde la libertad de escoger y de hacer le llevan a alcanzar niveles más evidentes en sus últimas obras, de intimismo, sencillez y frescura que a mi juicio es donde está su verdadera entidad como pintor" 1 .

Su pintura histórica, como se expuso líneas atrás, se halla fundamentalmente en Venezuela. El propio artista comenta al respecto que este género pictórico, tan propio del Ochocientos, "Yo lo he hecho a mi aire y a mi manera"18. En tan sugestivo capítulo podríamos citar: La fundación de la ciudad de Trujillo, en el Ayuntamiento de Trujillo (1956); Firma de la independencia de la ciudad de Trujillo, en el Consejo principal de Trujillo (1957); Recibimiento de Juan de Ampies por el cacique Manaure, en la

15. LORENTE, Manuel: "Juan Antonio Rodríguez y su constante lección de belleza", en $A B C$. Sevilla, 16-VI-1984, pp. 44-45.

16. "Antología Crítica", en Juan Antonio. Tabapress, Grupo Tabacalera. Op. cit., p. 18.

17. Ibídem, p. 21.

18. MERCHÁN DIAZ, M. : "Juan Antonio Rodríguez. El último pintor sevillano", en Rev. Antiqvaria. Año X. N 99. Madrid, 1992, pp. 36-42. 
colección particular de Mons. Victor J. Pineda (1959); Fundación de Maracaibo, en la Universidad de Zulia (1960); Don Luis de Villegas inicia la encomienda de San Juan de Carache (1961); Descubrimiento del Valle de Boconó, en Boconó (1963); etc.

Su pintura mitológica, realizada fundamentalmente entre 1980 y 1990 , refleja sin más el amor por lo bello y la percepción de lo clásico. En su Olimpo sevillano, las deidades paganas, las ninfas y los faunos, coronados de pámpanos y guirnaldas florales, aparecen animados por el espíritu grecorromano y por la mediterraneidad que subyace en todo los andaluz.

En este sentido, Carlos García-Osuna apunta que "Diana, Venus, sátiros y ninfas se arraciman una y otra vez en la cosmogonía del artista sevillano, que quiere con su pincelada, tenue y no impactante, sugerir una imagen, desvelar un apartado del misterio, usando la sabiduría clásica para pertrechar emociones, ensoñaciones, y melancolías..." 19 .

En el tema de la mitología — griega y latina_ Juan Antonio interpreta, de forma humanizada e íntima, el conflicto, el heroísmo, la pasión, etc., de unos personajes que, hoy como ayer, gozan de palpitante actualidad. Entre estas obras podemos reseñar: Sevilla pagana, -Apolo coronado de rosas-, en colección de los Duques de las Torres, Madrid (1979); Las ninfas, en colección particular de Antonino Parrilla, Sevilla (1979); Amorcillos con orla de flores, en colección particular de los Sres. de la Cruz, Sevilla (1984). El despertar del fauno, en colección particular, Bilbao (1990); y Cástor y Pólux, en colección particular del artista, Sevilla (1990).

Los cuadros de costumbres de nuestro pintor mantienen el regusto del costumbrismo romántico sevillano, cultivado por los Bécquer, Rodríguez de Guzmán y Cabral Bejarano, etc. Las escenas, tomadas siempre del folklore andaluz, recrean deliciosas estampas populares. El dibujo correcto y la pincelada suelta propician una técnica vaporosa. $\mathrm{Su}$ paleta, multicolor y jugosa como siempre, hace gala de un vocabulario que favorece el juego de luces y sombras, el elemento anecdótico y la calidad y lujo de la indumentaria. Los toreros, bandoleros, gitanillas, majas, etc. responden, como era de esperar, al consabido optimismo, generosidad y alegría de su pincel. Por ello, Javier González de Vega, en la polifacética labor de Juan Antonio Rodríguez, destaca las composiciones "románticas" que el propio artista, muy graciosamente, llama "piropos" 20.

Tan bello y entrañable capítulo del buen hacer de este pintor sevillano, que prolonga el estilo hasta nuestros días, podría ilustrarse con las siguientes obras: Entrada en la plaza de toros de la Real Maestranza de Sevilla y Fiesta en una venta, en colección particular de Sebaldo Pérez, Sevilla; Antiguo mercado sevillano, en colección particular de Esteban Martínez Polo, Sevilla; Seises de la Catedral de Sevilla, colección de S. A. R. la Condesa de Barcelona, Madrid: El camino viejo de Castilleja de Guzmán, en colección particular del Sr. González Escobal, Sevilla (1989); y El bolero, en el Ayuntamiento de Bollullos par del Condado (Huelva) (1993).

19. GARCÍA-OSUNA, Carlos: "Desde la mitologia", en diario El independiente. Madrid, 5-XI-1990, p. 50.

20. GONZÁLEZ DE VEGA, Javier: "Juan Antonio, Del amor al arte", en Rev. Miguelangel n 14. 1994, pp. 19-30. 
Durante el romanticismo se presta especial atención al paisaje, ya que orilla la cotidianidad de la vida y exalta la fantasía. Juan Antonio, como lo hiciera Pérez Villaamil, se deja seducir por la realidad de los parajes pintorescos y evocadores. A veces, dando rienda suelta a su imaginación, acentúa y prodiga los pormenores y efectismos de la panorámica urbana o campestre. Su fácil factura, de líricas ensoñaciones, fomenta sin duda la fantasía creadora del autor.

Este género pictórico es infrecuente en la dilatada producción del artista que nos ocupa. Sobre este particular, el mismo recuerda que en Mallorca pintó ocho paisajes y que en Guadalupe volvió a cultivar dicho tema. Sin embargo, aunque afina mucho la paleta, afirma: cuando regreso "me encierro aquí, donde tengo la pintura de dentro, de interior, bodegón, retrato, figura. Todo eso es mi mundo" 21

A raíz de cuanto expuesto queda, Pilar Palomares Quesada hace especial hincapié en que "Sus obras de la etapa mallorquina: Paisaje de Mallorca y la Virgen Mediterránea, de los años 1949 y 1950 respectivamente, no pueden pasar desapercibidas, ya que suponen un paréntesis en lo que es su estilo, muy arraigado en la tradición pictórica sevillana, tanto en su impresionante colorido como en la aparición de un paisaje, tema que escasea en su variada producción" ${ }^{22}$.

En la reducida nómina de los paisajes de Juan Antonio podemos destacar los siguientes cuadros: Paisaje de Mallorca, en colección particular de los Sres. de Cubiles, Sevilla (1949); Ruinas monumentales de Roma, en colección particular de Faustino Gutiérrez-Alviz, Sevilla; Vista de Amsterdam, en el Ayuntamiento de Carmona (Sevilla); y dos Paisajes con árboles, en colección particular de Pablo Gutiérrez-Alviz Conradi, Sevilla.

Sin lugar a dudas, Juan Antonio es uno de los retratistas sevillanos más significativos del momento. La sólida y exquisita formación artística recibida le acreditan como un experto cultivador de este género pictórico. Técnicamente, mantiene la corrección del dibujo y el colorido suave y luminoso que le caracterizan. Ello justifica, sobradamente, que una gran clientela, nutrida por la aristocracia y la burguesía, demande con insistencia sus retratos. Es obvio que todos ellos, en especial los femeninos, reflejan la elegancia y el encanto del modelo. Y busquen siempre la armonía entre el condicionamiento físico y el estudio psicológico del personaje. En definitiva, nuestro pintor "retrata con la misma unción a una Infanta de España, que a la niña de un marinero de Triana, con carita de Virgen de Murillo y sonrisa de ninfa" ${ }^{23}$.

Rafael Manzano Martos comenta al respecto que Juan Antonio "es un pintor esencialmente culto que a veces nos traslada con su magia al frívolo mundo de la Venecia de Tiépolo o nos encierra en el mundo devoto de la pintura religiosa, sin dejar al margen el alegre mundo del costumbrismo post-goyesco. Majos y Manolas

21. MERCHÁN DÍAZ, M.: "Juan Antonio Rodríguez. El último pintor sevillano", Op. cit., pp. 36-42.

22. PALOMARES QUESADA, Pilar: "Juan Antonio. La realidad hecha arte",en Rev. Antiqvaria. Año VIII. No 78. Madrid, 1990, pp. 88-90.

23. GONZÁLEZ DE VEGA, Javier: "Manuscrito", en Juan Antonio. Tabapress, Grupo Tabacalera. Op. cit., p. 6. 
vuelven a convertirse en sus lienzos en tema eterno. Pero dejemos estos recuerdos de recreación historicista, serena y reposada para volver al enfrentamiento con la realidad: el retrato, que cada día cultiva nuestro artista con mayor calidad, especializándose en esos retratos de niños donde la figura humana no flota ingrávida sobre esos fondos neutros a los que nos tienen acostumbrados los retratistas convencionales, sino que se convierte en elemento vital, en diálogo con su paisaje" ${ }^{24}$.

Entre sus retratos destacan los de SS. MM. los Reyes de España, D. Juan Carlos I y Dña. Sofía, para el Ayuntamiento de Sevilla (1976); otro del mismo monarca para el Ministerio de Obras Públicas, en Madrid; el de S. A. R. la Infanta Margarita de Borbón, en la colección de los Duques de Soria, Madrid (1980); y el de S. A. R. Diana de Francia, duquesa de Württemberg, en Mallorca (1995). El artista posee, además, interesantes ejemplares de este género pictórico en las colecciones particulares de los Duques de Santisteban del Puerto, Sevilla (1988); Conde de Lebrija, Sevilla (1994); Sres. Ternero y Pablo-Romero, Sevilla: Sres. de Velasco, Sevilla (1988); Sr. González Escobal, Sevilla (1985); etc. Mención especial merecen los retratos de Juan Ramón Jiménez (1955), inspirado en el que Sorolla le hizo en 1916, para la galería de retratos de la Biblioteca Provincial Universitaria de nuestra ciudad; el del Cardenal Bueno Monreal, en la actual sede de El Correo de Andalucía, Sevilla (1977), y el de Mons. González Moralejo, Obispo de Huelva, en el Seminario Onubense (1984); así como los de los profesores Suárez Perdiguero y Clavero Arévalo, en la colección de Rectores de la Universidad de Sevilla. Y, para concluir esta apretada síntesis, debemos hacer constar que tiene retratos en México, Venezuela , Puerto Rico y Nueva York.

En España, entre 1590 y 1620, florecieron afamados pintores de bodegones y floreros. Sus composiciones, dotadas de gran simetría, sobriedad y misticismo, arrancan de la pintura flamenca del Quinientos. En Sevilla, sus máximos exponentes son Zurbarán y Camprobín. Los bodegones de Juan Antonio, no exentos de modemidad, mantienen lo mejor de la tradición barroca. Las frutas expuestas en fuentes, platos y tazas están tomadas de Zürbarán. Por el contrario, la cacharrería disiente de la tipología zurbaranesca, aunque sí responde a ella la ambientación del tema: fondo en penumbra, iluminación lateral izquierda, nítido perfil de la mesa, florecillas sueltas, etc.

Al combinar flores y frutas con cristal y cerámica, sus composiciones pierden sobriedad y, por consiguiente, ganan en refinamiento. Los fondos se iluminan directamente. El cristal, tan del gusto del artista, se hace más transparente. Y la cerámica adqüiere calidades aporcelanadas. Estos logros son posibles gracias a una técnica suelta, ágil y ligera, que se contrapone a la empleada en los bodegones cuyas. formas prietas, definidas y rotundas son propias del siglo XVII.

El pintor deja volar su imaginación y fantasía cuando se enfrenta sólo y exclusivamente al tema floral. Las flores, respaldadas por un fondo neutro o rojo pompeyano, se distancian de la estética tradicional del bodegón sevillano. En tan amorosa 
exaltación de la naturaleza, las rosas multicolores y los jazmines blancos y celestes viven y justifican, ante el espectador, su poder de fascinación.

En resumen, los bodegones y floreros de Juan Antonio son "pinturas que no quieren vivir sólo impresionadas por la luz, sino también emocionadas de color en una forma acabada por la belleza. En ellos, todo se hace poesía, hasta tal punto que "los jazmines con su blancura pequeña" nos traen el embrujo lorquiano; y las rosas son tan perfectas, que podríamos decir como Juan Ramón: que "todas las rosas son la rosa" o que "en el aroma de esta rosa nos vamos al infinito" 25.

Bellos ejemplos de cuanto hemos comentado son el bodegón sacro, Vas Honorabile, en la colección de los Duques de Soria, Madrid (1979); Homenaje a Zurbarán, en la colección de los Marqueses de Isasi, Madrid (1979); Barro y jazmines, en la colección Dávila-Ponce de León, Madrid; Bodegón con figura, en la colección de los Sres. Gutiérrez-Alviz, Sevilla (1962); Bodegón de la copa de plata, en colección de los Sres. de Melendo, Sevilla (1972); Bodegón, en la colección del Conde de Casa Galindo, Sevilla; Jazmines y cristal, en la colección de los Sres. de Vega, Madrid (1984); Jazmines heráldicos, en la colección de los Duques de Huesca, Madrid (1988); Flores y mariposas, en la colección del Sr. González Escobal, Sevilla (1993); Tondo de flores, en la colección de los Sres. Ternero y Pablo-Romero, Sevilla; Flores, cristal y plata, en la colección de los Sres. Femández Heredia, Sevilla (1995), etc.

Para completar esta panorámica del estilo y la obra de Juan Antonio Rodríguez debemos recordar, como apunta Merchán Díaz, que "alejados de modas, movimientos artísticos y de los circuitos comerciales, el artista pinta, por encargo, numerosos retratos, cuadros con motivos religiosos y de historia, y bodegones. Su forma de ser y hacer le configuran como el último pintor propiamente sevillano" 26.

Sobre el particular abunda González de Vega al comentar que el maestro, como cariñosamente le llaman todos, "metido en su delicioso estudio, rodeado de lo que le gusta, tranquilo consigo mismo va realizando una labor callada e ingente. Su única ocupación es la pintura. Lo demás son ratos de asueto... Y así pasa por las fiebres de los ismos y las modas. A veces, como ejercicio de humor, o reto a sí mismo, hace pintura abstracta, o pop. Pero ese juego lo guarda para sî" 27 .

Precisamente, en este punto, resultan muy esclarecedoras las declaraciones del propio pintor: "me divertí mucho haciendo seis cuadros abstractos por encargo de un arquitecto amigo mío. Entonces yo estaba pintando a Zóbel, fijate, un retrato que le hice para Manila, para una casa que tenía allí. Vió el primer cuadro abstracto que hice y me dijo que yo había hecho el barroco en el abstracto, algo muy difícil de hacer". Y a continuación explica que Zóbel, gran amigo suyo, le aconsejo: "donde no tengas nada que poner, no pintes nada, ¿para qué? Yo gustaba mucho de rellenar todo el cuadro con cosas, y él me hizo ver que el argumento se basaba en ciertos puntos, y que lo demás sobraba. No he hecho más porque no me gusta, no era lo

25. GONZÁLEZ GÓMEZ, Juan Miguel: Juan Antonio. Floreros y Bodegones. Op. cit., p. 1.

26. MERCHÁN DÍAZ, M.: “Juan Antonio Rodríguez. El último pintor sevillano”. Op. cit., pp. 36-42.

27. GONZÁLEZ DE VEGA, Javier: "Juan Antonio. Del amor al arte". Op. cit., pp. 19-30. 
mío, pero sí es muy distraído. Lo que sí he hecho es servirme del abstracto para hacer mis cuadros realistas..." 28.

Y para finalizar, hacemos nuestras las palabras del profesor Hernández Díaz, que dice haber seguido durante más de cuarenta años la trayectoria artística de Juan Antonio y "comprobado venturosamente su rigor, seriedad, disciplina, lealtad a sus principios y fundamentos estéticos, ajeno por completo a los cantos de sirena que a tantos descarrían, en busca de una pretendida modernidad que muchas veces es más ficticia que real. Sus viajes por la Geografía hispánica y la italiana, entre otros, se acusan en su evolución estilística" ${ }^{29}$.

\section{LA ASUNCIÓN DE MOGUER}

El pasado día 8 de septiembre de 1995, don Manuel Castilla Bonaño, párroco de Moguer, bendijo un gran cuadro de la Asunción de Nuestra Señora, en la Iglesia Mayor de Santa María de la Granada, de dicha ciudad. La pintura, obra de Juan Antonio Rodríguez Hernández, la encargó el referido sacerdote al comenzar el año $1993^{30}$. Y, una vez concluida, se instaló en la tribuna superior del presbiterio, que en origen contó con un espléndido órgano de tubos destruido en 1936. El marco de escayola lo hizo en Moguer, según el perfil mixtilíneo facilitado por el propio pintor, Antonio Oliad Ramírez. Y en las labores del dorado intervinieron el dorador sevillano Mariano Rojo y el artista moguereño Joaquín Mora Cruzado.

La escena se atiene a la iconografía tradicional del tema. No se sabe, con certeza, a qué edad falleció María. Según San Epifanio, contaba 72 años cuando ocurrió el b́bito $^{31}$. Noticia que sostiene Francisco Pacheco ${ }^{32}$. Por el contrario, otros apuntan que la muerte le sobrevino a los 60 años, mientras los apóstoles predicaban por Judea y sus alrededores ${ }^{33}$.

La literatura apócrifa abunda sobre el particular. Un viernes, en que, como de costumbre, la Virgen oraba ante el sepulcro de su Hijo, el arcángel Gabriel le anunció que su fin estaba próximo. Entonces, Ella rogó que le enviasen a Juan y a los demás apóstoles, para despedirse de ellos. De inmediato, todos regresaron; e

\footnotetext{
28. MERCHÁN DÍAZ, M.: "Juan Antonio Rodríguez. El último pintor sevillano". Op. cit., pp. 36-42.

29. HERNÁNDEZ DÍAZ, José: "Prólogo", en Juan Antonio. Tabapress, Grupo Tabacalera. Op. cit., p. 13.

30. Archivo Parroquial Moguer: Carpeta AZ de facturas. El primer documento relativo a este cuadro es del Banco de Granada, fechado en Moguer a 10 de enero de 1993, se trata de un ingreso para abono en cuenta efectivo a favor de D. Juan Antonio Rodríguez Hernández de 250.000 ptas. por entrega del Sr. Cura Párroco de Moguer. El encargo se efectuó por indicación del poeta moguereño Francisco Gárfias López y del pintor sevillano Miguel Ballesta Maqueda.

31. VORÁGINE, Santiago de la: La leyenda dorada, 1. $2^{\mathrm{a}}$ edición en Alianza Editorial. Madrid, 1984, p. 477.

32. PACHECO, Francisco: Arte de la Pintura. Año 1638. Ed. de Francisco Javier Sánchez Cantón. Madrid, 1956, p. 297.

33. VORÁGINE, Santiago de la: La leyenda dorada, 1. Op. cit., p. 477.
} 
incluso, los ya fallecidos retomaron a la vida terrena. Se reunieron en Belén y desde allí marcharon a Jerusalén, donde vivía la Madre del Señor. Ya en casa de María, un domingo, se presentó Cristo para recibir su alma. Entre tanto, Pedro recitaba el aleluya en la cabecera del lecho; y Juan, de rodillas, rezaba a los pies del mismo. Luego, enterraron su cuerpo en Getsemaní, de donde subió gloriosamente a los cielos.

Hasta aquí, la versión del Pseudo Juan Evangelista ${ }^{34}$. El relato del Pseudo Juan, arzobispo de Tesalónica, aporta el detalle de la palma que el ángel entrega a María en señal de su inmediata partidả. Y el Pseudo José de Arimatea recoge la tradición de que Tomás no pudo llegar a tiempo cuando María era transportada por los aires, y entonces Ella le concedió el cinturón con que los apóstoles habían ceñido su cuerpo ${ }^{35}$.

Esta tradición, que se remonta a los mismos tiempos apostólicos, está confirmada por los escritos patrísticos de los siglos IV y V. En el siglo VI existe ya una fiesta litúrgica de la Dormición de la Virgen. Desde entonces, a lo largo del medievo, se va imponiendo la aceptación del misterio. Así, en el siglo XIII, la Leyenda Dorada, libro muy consultado por los artistas, retomó con nuevos bríos aquella historia apócrifa. Y la Asunción surge, por consiguiente, como la continuación del relato de la Muerte de la Virgen.

Jacobo de la Vorágine comenta que al tercer día del fallecimiento de María, estando los apostoles junto a su enterramiento, se les apareció Cristo acompañado por el arcángel San Miguel, que portaba el alma de la Virgen. "En aquel instante el alma de María se aproximó a su cuerpo y éste, vivificado nuevamente, se alzó glorioso, salió de la tumba y entonces mismo la Señora, acompañada y aclamada por infinidad de ángeles, subió a los eternos tálamos" ${ }^{\prime 36}$. Razón por la que el tema asuncionista se cultivó con profusión en el arte gótico a partir del siglo XIII, especialmente en la decoración escultórica de los pórticos de las iglesias dedicadas a la Virgen. Posteriormente, se consagró como un asunto importante del arte sacro. Durante el Renacimiento y el Barroco se prodigan las representaciones del mismo. Entre sus máximos exponentes pictóricos figuran Tiziano y Rubens. Y en la escuela sevillana, entre otros, destacan Juan del Castillo, Bartolomé Esteban Murillo y Juan de Valdés Leal.

Como era de suponer, el arte religioso, fiel reflejo de la fe y devoción del pueblo, consagra una iconografía específica. Y los teólogos latinos terminan haciendo suya esa aceptación general. Por ello, en 1950, el Papa Pío XII, ante tan unánime consentimiento, proclama solemnemente como verdad dogmática "que la inmaculada Madre de Dios, siempre Virgen María, cumplido el curso de su vida terrena, fue asunta en cuerpo y alma a la gloria celestial" ${ }^{37}$.

El gran cuadro de la Asunción de Moguer constituye, sin duda alguna, una buena síntesis de cuanto expuesto queda sobre el particular. El autor, desde el punto de vista técnico, tuvo que superar ciertas dificultades. El soporte, cuyo formato es

34. SANTOS OTERO, Aurelio: Los evangelios apócrifos. B. A. C. Madrid, 1985, pp. 582-606.

35. Ibídem, pp. 607-645 y 646-659.

36. VORÁGINE, Santiago de la: La leyenda dorada, 1. Op. cit., p. 481.

37. PÍO XII: Const. Apost. Munificentissimus Deus, 1-XII-1950. Doc. Mar. n. 812. 
de medio punto, se compone de doce fragmentos de madera. En realidad, es una estructura contrachapada sobre bastidores finos y gruesos. Las láminas son de $2 \mathrm{cms}$. de grosor. Sobre ellas se aplicaron varias capas de selladora y, luego, se pintó directamente al óleo. La labor de carpintería la ejecutó José Durán, en Camas, localidad próxima a Sevilla.

Previamente, el artista hizo un preboceto sobre papel. Y, acto seguido, proyectó el boceto, 6́leo sobre conglomerado (alto, $1,65 \mathrm{~ms}$.; ancho, $1,10 \mathrm{~ms}$ ) ${ }^{38}$. Sobre este último resolvió todos los problemas técnicos. Cambió posturas, perspectivas, colores, etc. (Lám. 1). La escena se trasladó al cuadro definitivo (alto, 7,5 ms.; ancho, $5 \mathrm{~ms}$.) por el procedimiento de la cuadrícula, reproduciéndola con toda fiabilidad (Lám. 2). Así se subsanó la dificultad emanada de la fragmentación del soporte, que impedía una visión integra del total resultante. (Lám. 3).

En la línea de tierra, en torno a la sepultura, se disponen los apóstoles en grupos de tres. A la izquierda, en primer plano, se sitúan: Juan Evangelista, joven y apuesto, de pie; Bartolomé, de tez morena, arrodillado y reverente ante la tumba; y Andrés, de pelo y larga barba blanca, expectante ante el suceso. Detrás aparecen los hermanos Simón y Judas Tadeo que, según la tradición popular, estaban entre los pastores a quienes el ángel anunció el Nacimiento del Mesías; y Felipe, que, por ser muy joven, se representa sin barba. A la derecha, se agrupan escalonadamente: Santiago el Menor, de noble empaque y actitud contemplativa; Pedro, en 'genuflexión simple, con pelo y barba corta y canosa como corresponde a un pescador; y Mateo que, arrodillado, mira insistentemente el interior del sepulcro. Al fondo, completan el Sagrado Colegio Apostólico, Santiago el Mayor que también observa piadosamente el túmulo vacío; a su lado está el incrédulo Tomás, como es preceptivo, sin barba; y junto a éste, Matías, el sustituto del desventurado Judas Iscariote.

Todos estos personajes, perplejos, quedan perfectamente conjuntados gracias a la expresión de los rostros y a la elocuencia de los gestos corporales. En sus actitudes se reflejan la sorpresa, el estupor y la devoción del momento. Se han respetado, en lo posible, ciertas convencciones sobre la apariencia física y la forma de agruparse ${ }^{39}$. En general, las cabezas son modelos imaginados por el autor. Sólo hay tres retratos, más o menos idealizados. Para Tomás posó el poeta moguereño Francisco Garfias López, Premio Nacional de Literatura; Matías está inspirado en Rosendo Arias León, amigo personal del artista; y Santiago el Mayor, Patrón de España, toma referencias del natural del autor de presente estudio.

En el rompimiento de gloria, la Virgen, sedente sobre un trono de nubes, es llevada amorosamente al cielo por los coros angélicos. María viste de jacinto y azul, al gusto concepcionista. Acorde con el arte de la Contrarreforma, flota en el aire y extiende los brazos mientras mira hacia arriba extasiada. Está rodeada por una jubilosa mandorla de ángeles mancebos, angelotes y querubines de progenie barroca. Y, en lo más alto,

38. GONZÁLEZ GÓMEZ, Juan Miguel: "El boceto de la Asunción del templo parroquial de Moguer, obra de Juan Antonio Rodríguez" en Rev. Monte Mayor. Moguer 1994, pp. 68-70.

39. HALL, James: Diccionario de temas y símbolos artísticos. Madrid, 1987, p. 307. 
revolotea la paloma del Espíritu Santo para conceder el triunfo definitivo y la bienaventuranza etema a la criatura más cercana a la Santísima Trinidad ${ }^{40}$.

El ritmo general de la composición, triangular, está reforzado por el color. Para romper la horizontalidad del apostolado, al centro, se crea un espacio luminoso. Y, además, con este recurso se acentúa el carácter ascendente de la Virgen, transportada por ángeles. En consecuencia, se contrapone la línea horizontal con la circular. Se impone, pues, el dinamismo del rompimiento de gloria sobre la masa estática de los personajes que rodean el sepulcro.

La entonación cromática del pasaje mariano que nos ocupa es propia de la escuela sevillana tradicional. Los colores superiores son más claros, transparentes y vaporosos para aligerar la impresión de movimiento y marcar el sentido aéreo, ingrávido y sutil de las figuras celestes. María es la imagen más luminosa del conjunto, ya que aparece glorificada.

En la mandorla distinguimos dos partes bien diferenciadas. El medio punto que, a modo de abanico, distribuye dos parejas de querubes junto al Paráclito; otra pareja de angelotes, a la izquierda; y uno sólo, a la derecha. Desde los brazos de la Asunta hacia abajo asoman cuatro angelitos, por flanco; y otro, debajo de la nube, está concebido a modo de atlante. El cuarto, por el costado derecho, recuerda el rostro de Lourdes González Bermúdez. Todas estas figuras infantiles se cubren con voladas cintas rosas, para unificar la visión del grupo y no alterar la contemplación del misterio.

Los dos ángeles mancebos, de contrapuestas y equilibradas actitudes, subrayan el esquema triangular de la composición. A veces, se suelen identificar con los arcángeles San Miguel y San Gabriel. El que aúpa el trono de la Asunción, por la izquierda, en el boceto vestía de amarillo. Sin embargo, en el cuadro definitivo, se sustituyó este color por el azul, para afinar el juego cromático de la escena. De esta manera, se produce un bonito arabesco desde el manto de la Virgen a la túnica del ángel y desde ésta a la de San Pedro. Ese mismo ritmo se repite con los tonos verdes. Y, finalmente, debemos reparar en la rivalidad entre la blancura de las nubes y el inmaculado sudario de María, que reposa sobre el borde superior del sepulcro. Precisamente, en el ángulo inferior del mismo firma y fecha su obra el autor: "Juan Antonio Rodríguez. Sevilla 1995".

Así, casi inadvertidamente, el artista conjuga con acierto la iconografía al uso con su interpretación personal, el sentimiento popular con la erudición teológica, y la tradición piadosa con el dogma. Y, además, lo narra todo con suma naturalidad. En la obra que nos ocupa se capta, sin más, el refinamiento estético, la depurada técnica del dibujo, la belleza de la composición, la poesía del color, la trasparencia lumínica y el efectismo atmosférico propios de la escuela pictórica sevillana de todos los tiempos. Obviamente, en la unión orgánica del profundo conocimiento de la tradición, de la observación del mundo cotidiano y de la curiosidad de lo por venir, hay que situar el estilo personal de este pintor sevillano, en cuya jugosa y limpia paleta se unifican armoniosamente pasado, presente y futuro.

40. ALASTRUEY, Gregorio: Tratado de la Virgen Santísima. Madrid, 1945, pp. 482-504. MARTÍNEZ, Pedro de Alcántara: María. II. 5. Asunción. Gran Enciclopedia Rialp. Madrid, 1973, pp. 89-92. 


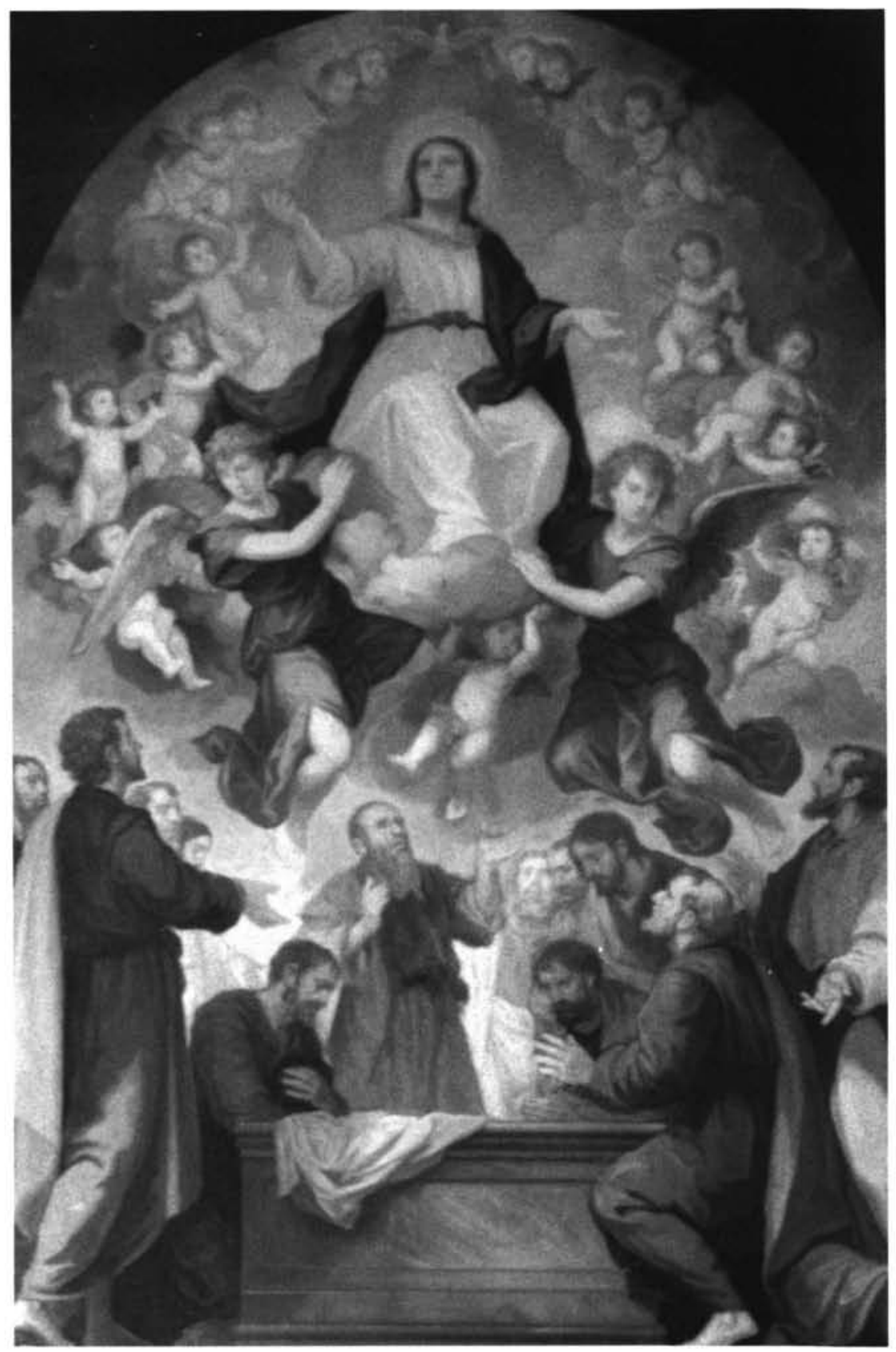

Lám. 1 


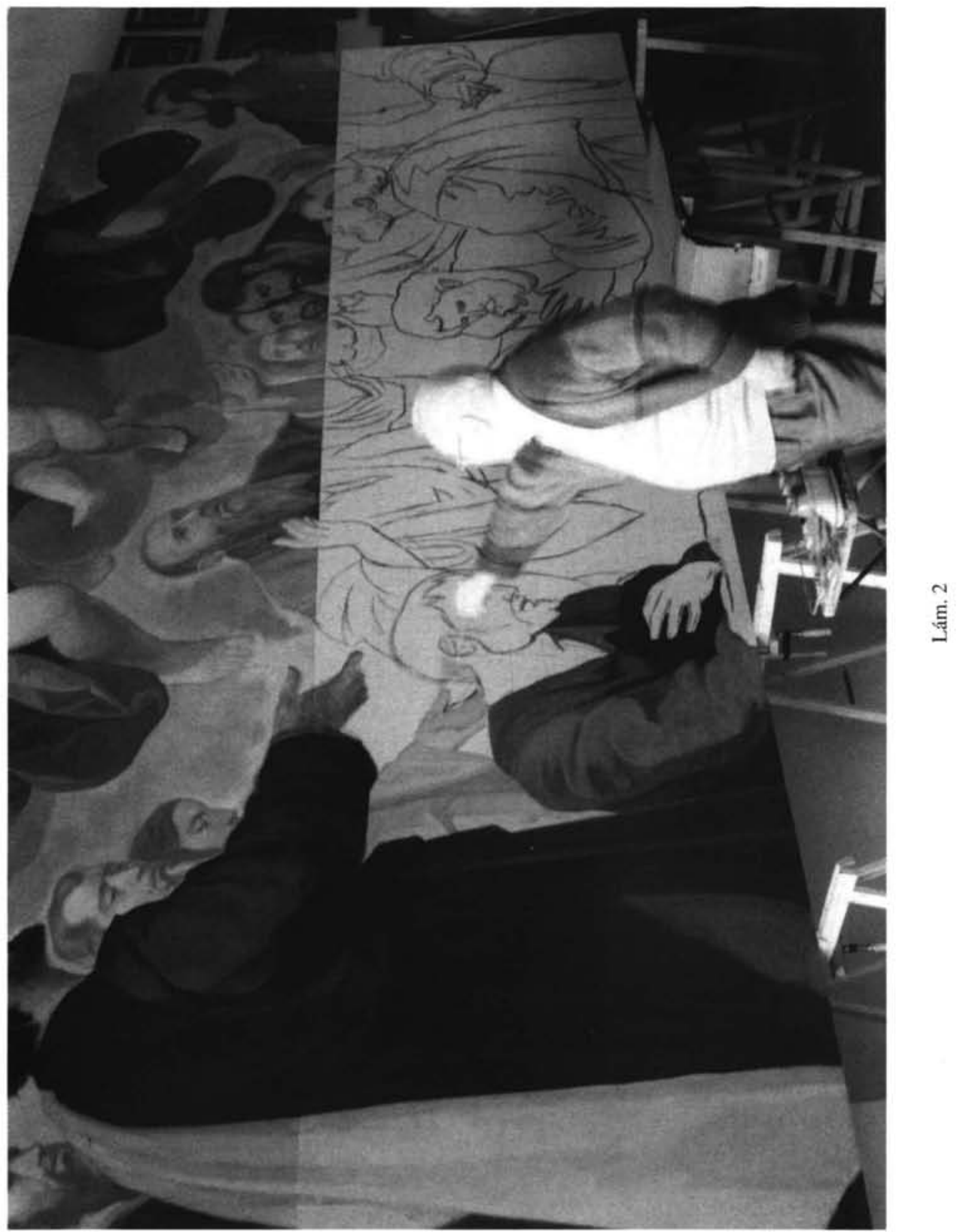




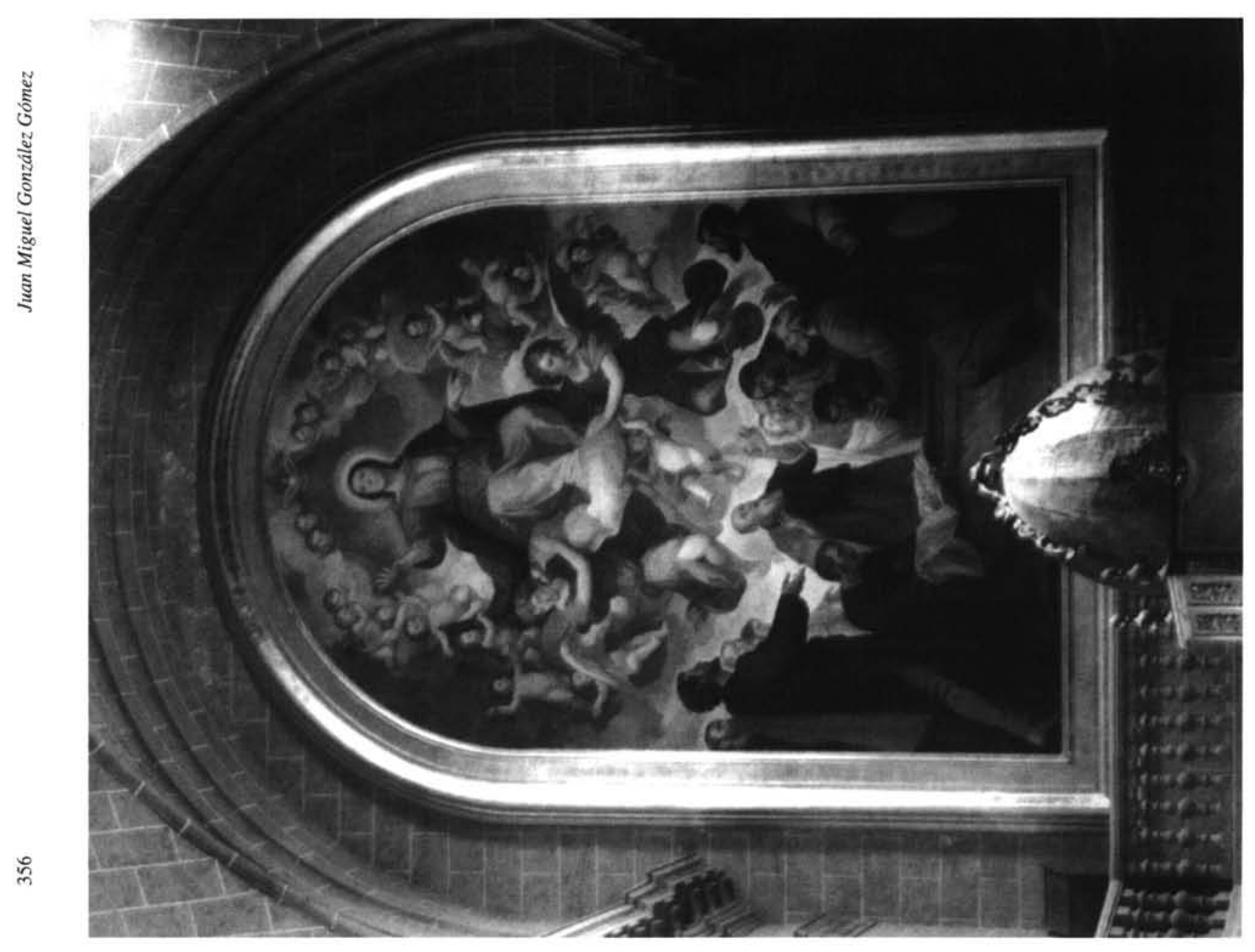

